\title{
Factor VIII Inhibitor-Bypassing Agents Act by Inducing Thrombin Generation and Can Be Monitored by a Thrombin Generation Assay
}

\author{
P.L. Turecek ${ }^{a} \quad$ K. Váradi ${ }^{a} \quad$ B. Keil ${ }^{a} \quad$ C. Negrier ${ }^{b} \quad$ E. Berntorp ${ }^{c} \quad$ J. Astermark ${ }^{c}$ \\ J.-C. Bordet $^{b}$ M. Morfini ${ }^{d}$ S. Linarid H.P. Schwarz ${ }^{a}$
}

aBaxter BioScience, Vienna, Austria; bHôpital Edouard Herriot, Lyon, France;

cUniversity Hospital Malmö, Malmö, Sweden; ${ }^{\mathrm{d} A z i e n d a ~ O s p e d a l i e r a ~ C a r e g g i, ~ F l o r e n c e, ~ I t a l y ~}$

\section{Key Words}

FEIBA · Factor VIla · Haemophilia A · Inhibitor · Thrombin generation $\cdot$ Prothrombinase $\cdot$ Activated prothrombin complex

\begin{abstract}
Factor VIII (FVIII)-bypassing agents have complex modes of action but all control bleeding in inhibitor patients by triggering the generation of thrombin. No routine test is available for monitoring this therapy in patients with inhibitors against FVIII. We present an assay that records FEIBA- or FVIla-mediated changes in thrombin generation (TG) in FVIII inhibitor plasma samples. In plasma samples spiked with FEIBA TG was normalized above $0.4 \mathrm{U} / \mathrm{ml}$, while for recombinant FVIla (rFVIIa) more than $12.5 \mu \mathrm{g} / \mathrm{ml}$ were required to induce TG in the absence of tissue factor (TF). Addition of TF increased the TG potential of rFVIla in vitro. This assay seems suitable for monitoring the pharmacokinetics of inhibitor bypassing agents during treatment and possibly for predicting responses to treatment.
\end{abstract}

Copyright $@ 2003$ S. Karger AG, Base

\section{Introduction}

Patients with haemophilia who develop inhibitors during replacement therapy with coagulation factor concentrates consequently fail to respond to the therapy and are treated with so-called bypassing agents to prevent or arrest severe life-threatening bleeding. In general treatment options currently include, among others, porcine factor VIII (FVIII), extracorporeal immune adsorption, and high-dose immunoglobulins [1-5], but treatment with the bypassing agents activated prothrombin complex concentrates (APCC) and factor VIIa (FVIIa) are the favoured options. The two corresponding products, FEIBA (Factor Eight Inhibitor Bypassing Activity - plasma-derived APCC) and NovoSeven (recombinant FVIIa, rFVIIa) have become mainstays for the treatment of inhibitor patients.

APCCs are composed of vitamin-K-dependent coagulation factor zymogens and traces of their activated enzymes. In contrast to multiple-component APCCs, FVIIa is a single-component protein therapy. Even FVIIa seems, however, to have at least two independent active principles: the tissue factor (TF)-dependent FVIIa-mediated activation of factor $\mathrm{X}(\mathrm{FX})$, which is the classic inducer of the extrinsic pathway of coagulation, and a TF-independent activity of high-dose FVIIa on endogenous phospholipid (PL) surfaces of monocytes or platelets [6]. FEIBA

Peter L. Turecek

Baxter BioScience, Industriestrasse 67

AT-1221 Vienna (Austria)

Tel +431201002520, Fax +43120100515

E-Mail peter_turecek@baxter.com
Fax + 41613061234

E-Mail karger@karger.ch www.karger.com
(C) 2003 S. Karger AG, Basel

Accessible online at: www. karger.com/pht 
also has multiple simultaneous modes of action. It triggers the formation of the prothrombinase complex, which leads to thrombin generation (TG). Feedback reactions mediated by thrombin and activated FX are thereby potentiated [7, 8]. In addition FVIIa-dependent FX activation similar to one of the active principles of pure FVIIa cannot be excluded.

Simple classic assays normally used to determine pharmacokinetics are not available for bypassing agents because of the complexity of their mechanism of action. The final product generated by bypassing agents is thrombin, thus a TG assay could be used for the assessment of the pharmacokinetic properties of those agents. There is no routine test that quantitatively assesses the thrombin forming capacity of a plasma sample. General clotting tests such as prothrombin time, activated partial thromboplastin time and the thromboelastogram $[9,10]$ do not reflect overall TG and are insensitive to hypercoagulation and possibly also hypocoagulation.

Hemker et al. [11] were the first to study the kinetic mechanisms of prothrombin activation in plasma and introduced the TG assay in 1986. Initially the TGA was mainly used to control anticoagulant therapies. In 1989, a platelet-based TG assay for measuring the bioavailability of FEIBA was proposed [12]. In the following year Gill et al. [13] were able to show clinical correlations between TG and the outcome of inhibitor bypassing therapy with APCC. Platelet prothrombinase activity might therefore predict successful treatment with APCC. In 1993, Sultan and Loyer [14] used such a TG test for in vitro evaluation of the FVIII-bypassing activity of APCC and FVIIa. Hemker et al. [15] defined the term 'endogenous thrombin potential' as the overall capacity of plasma to form thrombin after induction of coagulation, and this measurement was proposed as a sensitive indicator of every form of anticoagulation. Madlener et al. [16] subsequently found a strong correlation between the correction of the endogenous thrombin potential measured by the TGA and the clinical outcome of patients, thus providing further evidence in support of the TGA as an accurate and rapid method for monitoring inhibitor bypassing therapy with rFVIIa.

Figure 1 illustrates the changes in plasma thrombin concentrations as a function of the time course of the physiological events of coagulation. Upon exposure of damaged tissue, blood coagulation is triggered by $\mathrm{TF} /$ FVII complex. As a consequence of FX and FIX activation, activator complexes assemble on the activated platelet surface, and small amounts of thrombin are generated prompting fibrin formation. A short-lived equilibrium of thrombin activation and inactivation follows. The various feedback effects of thrombin's activation of FV, FVIII and factor XI produce a burst of TG (fig. 1a). After maximum TG is reached the physiological inhibitor systems (tissue factor pathway inhibitor, antithrombin, and the activated protein C-protein S system) slow down thrombin activation by inactivating the active enzymes and/or degrading their cofactors. Circulating inhibitors such as $\alpha_{2}$-macroglobulin inactivate thrombin itself. The thrombin concentration gradually decreases (fig. 1b). The rate of thrombin activation and the amount of peak thrombin depend on the relative rate of thrombin activation and inactivation mechanisms. Assay systems assessing the thrombin generation in plasma are suitable for detecting treatment-dependent changes in the kinetics of thrombin generation and allow the monitoring of the pharmacokinetic properties of inhibitor bypassing agents [17]. Therefore 'real time' measurement of the thrombin concentration that can be generated in plasma gives valuable information about the homeostasis of the coagulation system.

\section{Materials and Methods}

\section{Reagents}

FEIBA (APCC) was a product of Baxter BioScience, Vienna, Austria. rFVIIa (NovoSeven) was obtained from Novo Nordisk (Bagsvaerd, Denmark). We obtained human thrombin from Enzyme Research Laboratories (Lafayette, Ind., USA), frozen normal human plasma from George King Bio-Medical (Overland Parks, Kans., USA), recombinant TF from American Diagnostica (Greenwich, Conn., USA), high-titre human FVIII inhibitor plasma from Technoclone (Vienna, Austria). All other reagents and buffer components were commercially available reagents of highest purity.

\section{Plasma Samples}

Blood samples ( 9 parts added to 1 part of 3.4 or $3.8 \% \mathrm{Na}_{3}$-citrate) were taken and platelet-poor plasma was prepared by centrifuging the blood samples $(3,000 \mathrm{~g} / 20 \mathrm{~min})$. The plasma samples were frozen in aliquots at $-20^{\circ} \mathrm{C}$ and thawed at $37^{\circ} \mathrm{C}$ just before doing the assay.

\section{$T G$ Assay}

The thrombin generation assay was carried out as described [17] with minor modifications. Relipidated TF [18] was used as a trigger of TG. Figure 2 shows schematically the relipidation process of TF and a micrograph of the TF/PL vesicles. The reaction was started by the addition of FVIII inhibitor plasma. In the control experiment normal plasma was added. The peptide substrate is cleaved by thrombin, and fluorophore is liberated. The development of the fluorescence intensity at $37^{\circ} \mathrm{C}$, which is an indicator of the concentration of the generated thrombin, was monitored continuously. The rate of development of fluorescence intensity [fluorescence units (FU)] was calculated for each reading (FU/min), and converted to thrombin 


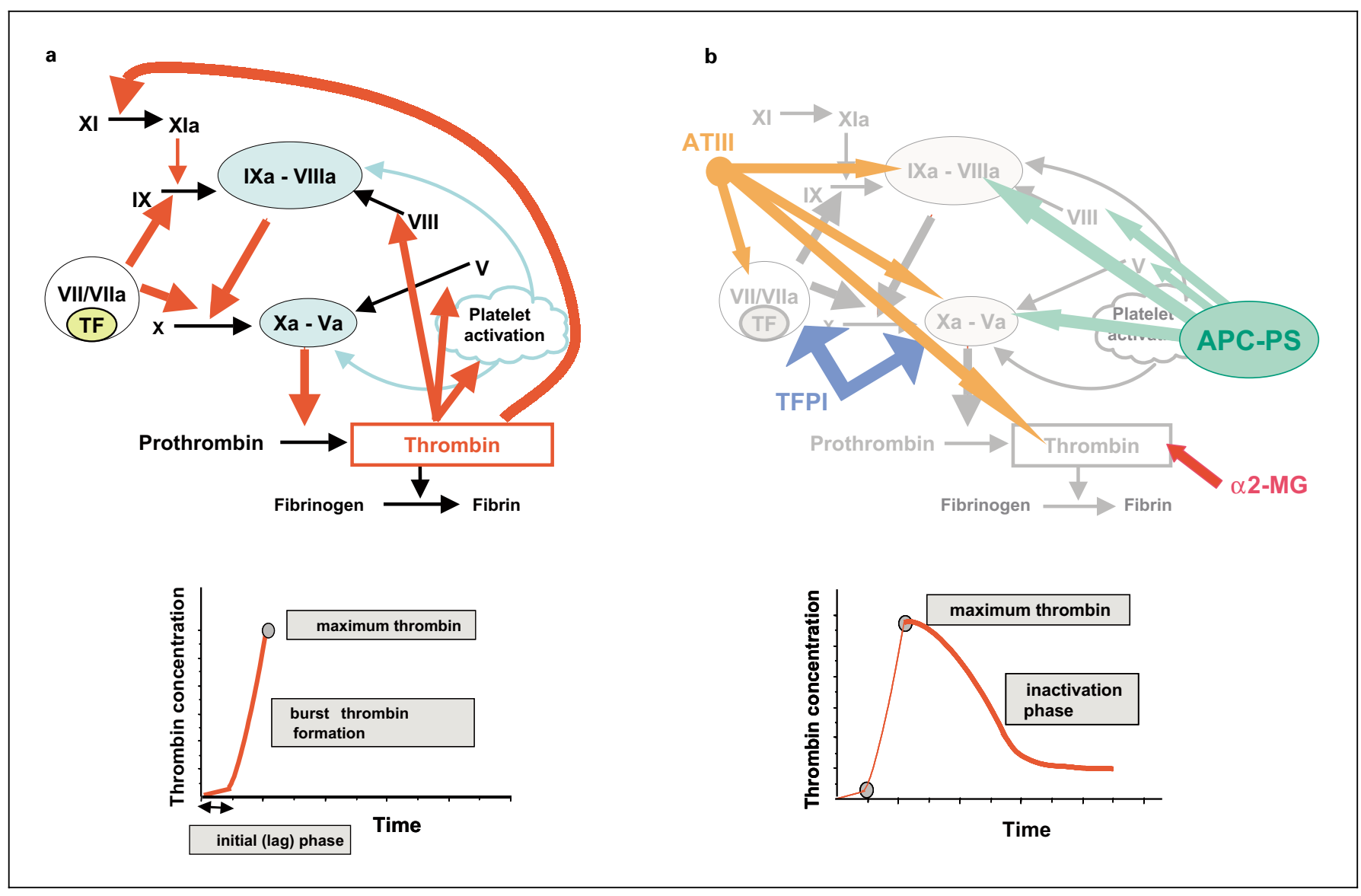

Fig. 1. Kinetic mechanisms of thrombin activation and inactivation during blood coagulation. Principles of TG assay. a Initiation of blood coagulation - thrombin activation. b Downregulation of thrombin generation. ATIII (antithrombin), TFPI (tissue factor pathway inhibitor), APC-PS (activated protein C-protein S), $\alpha 2-\mathrm{MG}(\alpha 2$-macroglobulin).

equivalent concentrations ( $\mathrm{n} M$ ) using a reference curve prepared by measuring the rate of substrate conversion by a purified thrombin added instead of the plasma sample. In some experiments a high-titre FVIII inhibitor plasma was supplemented in vitro with increasing concentrations of FEIBA or rFVIIa and thrombin generation was measured immediately. In another experiment increasing amounts of TF were added to the assay system.

\section{Results}

\section{Parameters of the TG Assay}

After the initiation of TG by relipidated TF and the addition of calcium, a continuous increase in the fluorescence intensity was observed during the online measurement. Because of the fluorogenic thrombin substrate present in the assay mixture, the accumulated effect of all the thrombin generated during the reaction period is detected. The rate of the increase in fluorescence intensity, i.e. the first derivative of the curves, reflected amidolytic activity of the sum of $\alpha_{2}$-macroglobulin-thrombin complex and free thrombin concentration, and showed the time-dependent activation and inactivation of thrombin as drawn schematically in figure 1.

There are different parameters of $\mathrm{TG}$, which characterize the TG curves. The peak thrombin is the highest thrombin concentration reached during the time course of thrombin formation and inhibition. In contrast, the thrombin potential is the amount of thrombin that is formed altogether within a certain period, e.g. $60 \mathrm{~min}$ (area under the TG curve). The lag phase and the peak time inform about the start and the velocity of the progress of thrombin formation. The exact calculation of the thrombin potential makes necessary the correction for the amidolytic activity of $\alpha_{2}$-macroglobulin-thrombin com- 
Fig. 2. Relipidated TF, the key reagent of TGA. Full-length recombinant TF was added to PL vesicles and the mixture was frozen at $-20^{\circ} \mathrm{C}$ overnight, and thawed for $30 \mathrm{~min}$ at $25^{\circ} \mathrm{C}$. The electron-microscopic photograph shows that the TF/PL complex consists of unilamellar vesicles of $200-300 \mathrm{~nm}$ diameter.

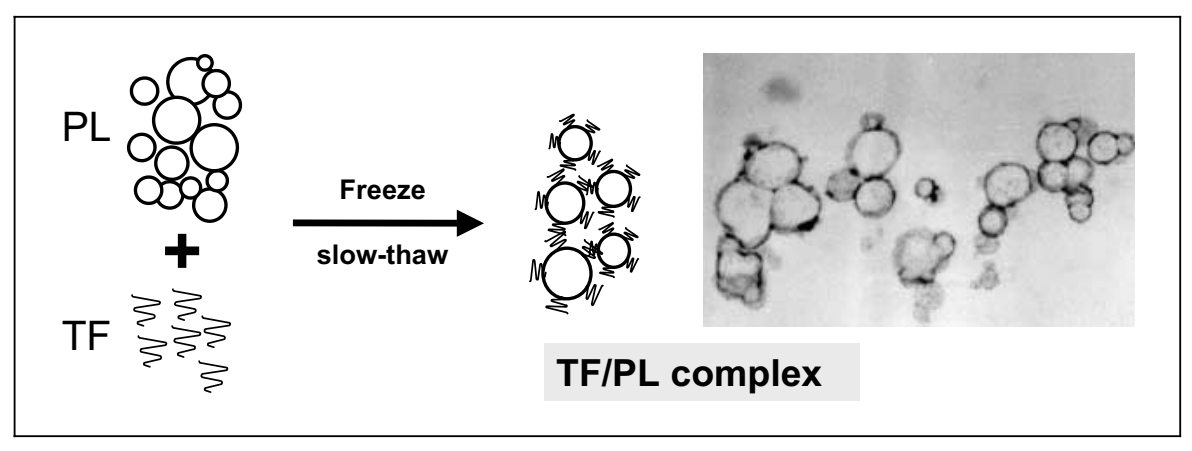

plex for substrate consumption and for the inner filter effect [see Hemker et al., pp. 4-15 (this volume)]. The calculation of the thrombin potential is, therefore, more complicated than that of the peak thrombin (maximum amidolytic activity), lag phase and peak time. Consequently we used these parameters to characterize TG in our study.

\section{Normal Range of $T G$}

TG was measured in the plasma samples of 39 healthy volunteers. The large array of measurements obtained in all parameters (table 1) indicated a broad normal range, defined by the means \pm SD.

\section{Effect of FEIBA and FVIIa on the TG of FVIII \\ Inhibitor Plasma in vitro}

High-titre FVIII inhibitor plasma was spiked with increasing concentrations of either FEIBA or rFVIIa and TG was measured as described in Materials and Methods. The TG curves drawn from the data from both preparations showed a dose-dependent increase in peak thrombin concentrations and thrombin potentials and a dosedependent decrease in the lag phases and the peak times (fig. 3).

The FEIBA and rFVIIa dose-response curves of peak thrombin were substantially different (fig. 4). In the FEIBA-spiked FVIII inhibitor plasma, normal peak thrombin concentrations were achieved when the FEIBA concentration corresponded to the calculated therapeutic doses (fig. 4a). In contrast, when high-titre FVIII inhibitor plasma was spiked with increasing concentrations of rFVIIa, normal peak thrombin values were reached with rFVIIa amounts higher than $12.5 \mu \mathrm{g} / \mathrm{ml}$ (fig. 4b). In another series of experiments, increasing amounts of TF were also added to the assay mixture in addition to rFVIIa. This additional TF dose-dependently increased the peak thrombin concentrations in the FVIII inhibitor
Table 1. Normal range of TG

\begin{tabular}{lcclc}
\hline & $\begin{array}{l}\text { Peak } \\
\text { thrombin } \\
\mathrm{n} M\end{array}$ & $\begin{array}{l}\text { Lag } \\
\text { phase } \\
\text { min }\end{array}$ & $\begin{array}{l}\text { Peak } \\
\text { time } \\
\text { min }\end{array}$ & $\begin{array}{l}\text { Thrombin } \\
\text { potential } \\
\text { at } 60 \text { min, FU }\end{array}$ \\
\hline Mean & 174 & 23.5 & 32.5 & 21,357 \\
SD & 88 & 8.9 & 13.2 & 6,363 \\
Minimum & 54 & 12.1 & 15.0 & 6,099 \\
Maximum & 411 & 45.4 & 66.0 & 31,432 \\
\hline
\end{tabular}

plasma supplemented with $1 \mu \mathrm{g} / \mathrm{ml} \mathrm{rFVIIa}$ and the normal range was reached at TF concentrations above $5 \mathrm{ng} /$ $\mathrm{ml}$ (fig. 5). In contrast, the presence of TF below $3 \mathrm{ng} / \mathrm{ml}$ had little if any effect on the TG induced by $0.8 \mathrm{U} / \mathrm{ml}$ FEIBA. The addition of higher TF concentrations dosedependently increased the peak thrombin resulting from both preparations.

The lag phase and the peak time were shortened substantially by both preparations, even at plasma concentrations far below the therapeutic range (not shown).

\section{Discussion}

FVIII-bypassing agents are used to treat patients with inhibitors against FVIII. No suitable method for monitoring the agents' efficacy and predicting the thrombogenicity of the therapy has yet been found. Therefore, an assay to measure the thrombin-generating capacity of plasma can be used to measure the efficacy of FVIII-bypassing agents in vitro and also in ex vivo samples from patients receiving treatment [17]. The TG assay was designed to result in normal TG in plasma from healthy donors but in almost no TG in FVIII-deficient plasma. This results in a high dynamic range of the assay and a high sensitivity in 


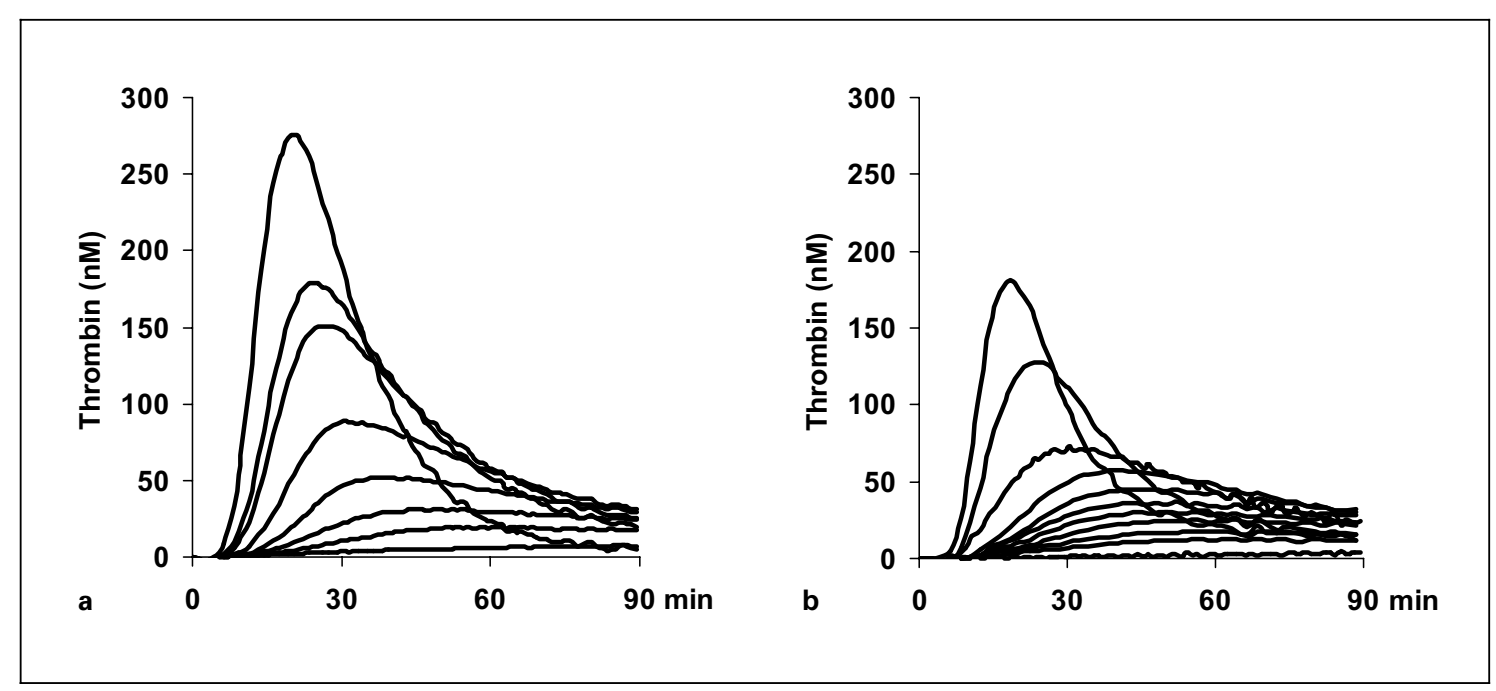

Fig. 3. Changes in TG in FVIII inhibitor plasma reconstituted in vitro with FEIBA and rFVIIa. a Concentrations of FEIBA in plasma from top to bottom: $2,1,0.8,0.4,0.2,0.1,0.5$ and $0 \mathrm{U} / \mathrm{ml}$. b Concentrations of FVIIa in plasma from top to bottom: $125,62.5,25,12.5,6.25,2.5,1.25,0.32,0.08,0.02$ and $0 \mu \mathrm{g} / \mathrm{ml}$.

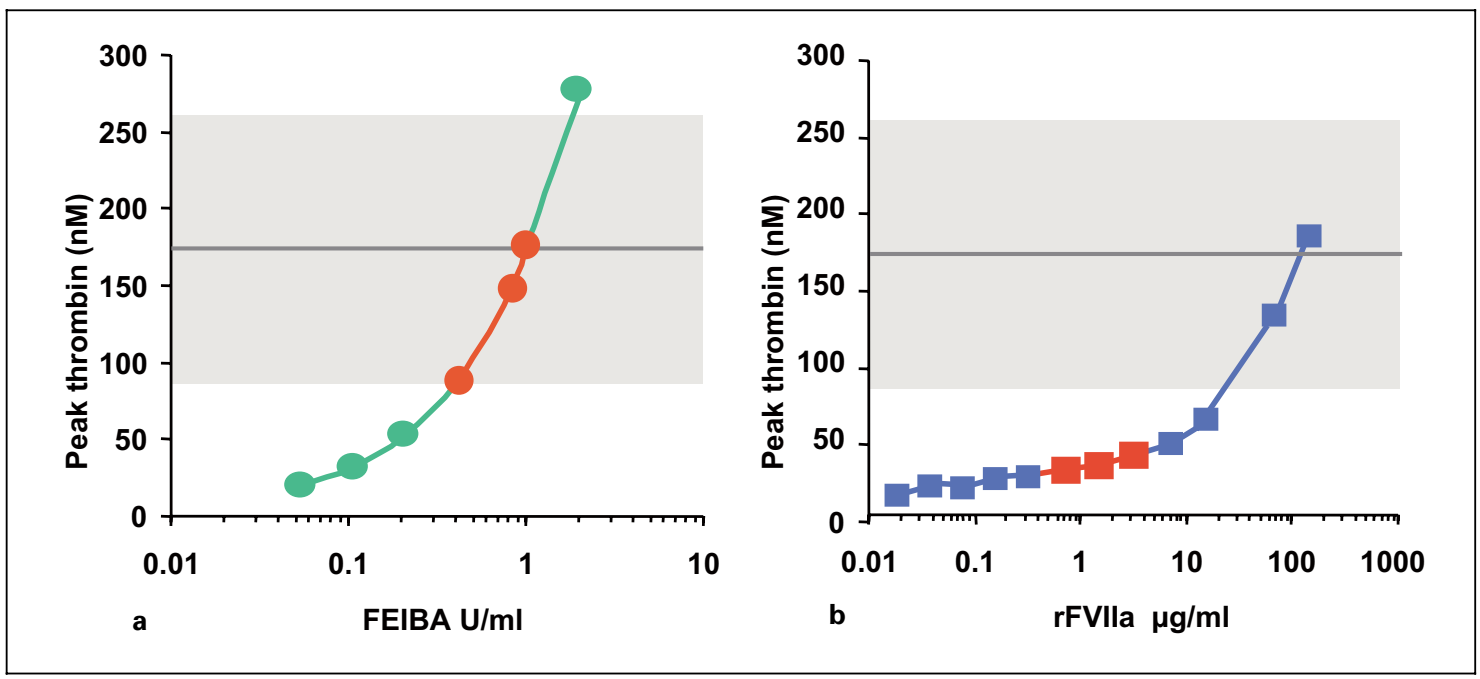

Fig. 4. Dose response of peak thrombin after in vitro FEIBA and FVIIa reconstitution in FVIII inhibitor plasma. a Dose-dependent increase of peak thrombin as a function of FEIBA concentration in plasma. b Dose-dependent increase of peak thrombin as a function of FVIIa concentration in plasma. Grey area represents normal range with the mean value of the thrombin peak indicated by a dark grey line. Red symbols represent the concentrations corresponding to therapeutic doses.

the low TG range. The assay principles are based on the work published by Hemker et al. [19].

We found that TG was restored in plasma to the normal range upon supplementation of FVIII inhibitor plasma with FEIBA concentrations equal to or above 0.4-
$1 \mathrm{U} / \mathrm{ml}$. On the assumption of a $50 \%$ recovery of the FEIBA product, $0.5 \mathrm{U} / \mathrm{ml}$ would be equal to a treatment dose of $40 \mathrm{U} / \mathrm{kg}$ body weight. The typical doses for treatment with FEIBA are around $65-100 \mathrm{U} / \mathrm{kg}$ body weight, which correlates well with the range in which TG was 
Fig. 5. TF dependency of TG in FVIII inhibitor plasma in the presence of FEIBA and rFVIIa. Peak thrombin measured in the presence of $0.8 \mathrm{U} / \mathrm{ml}$ FEIBA $(\bullet), 1 \mu \mathrm{g} / \mathrm{ml}$ rFVIIa (ם) and without any bypassing agents $(*)$. Grey area represents normal range with the mean value of the thrombin peak indicated by a dark grey line.

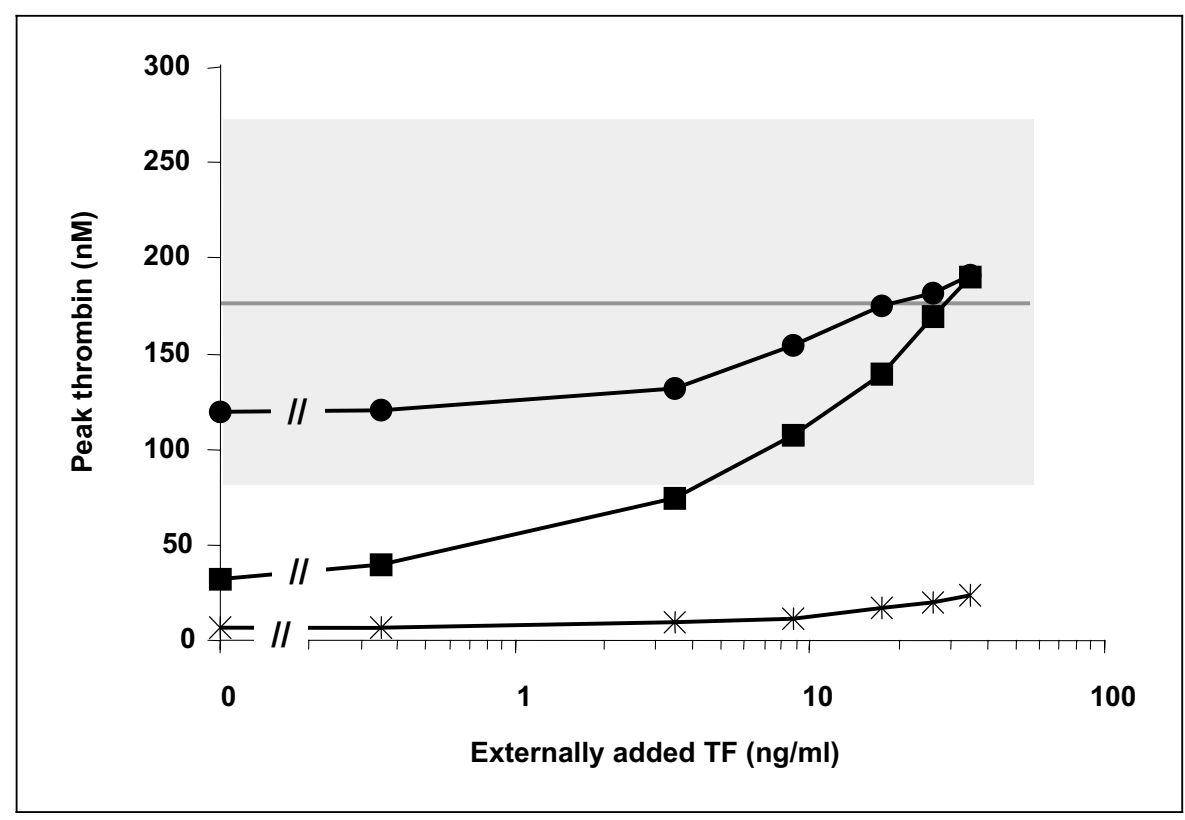

restored to normal in the in vitro study. When supplementing FVIII inhibitor plasma with rFVIIa we found TG normalized in FVIII inhibitor plasma above $12.5 \mu \mathrm{g}$ $\mathrm{FVIIa} / \mathrm{ml}$. The in vivo recovery of rFVIIa is not known but assuming a $50 \%$ recovery, our results indicate that more than $1,000 \mu \mathrm{g} / \mathrm{kg}$ rFVIIa would be required to normalize TG. This dose seems fairly high but in a recent preclinical animal study Kristensen et al. [20] showed that high doses of $600-1,200 \mu \mathrm{g} / \mathrm{kg}$ rFVIIa were required to control bleeding upon a single dose in a rabbit model of antibody-induced haemophilia A. Furthermore, the current trend is to give higher doses of rFVIIa than the originally recommended treatment dose of approximately 90 $\mu \mathrm{g} / \mathrm{kg}$. Successful use of FVIIa has been described with doses of $200 \mu \mathrm{g} / \mathrm{kg}$ and above [21-23].

In our TG assay system the relipidated TF concentration is $1.79 \mathrm{p} M$, which is in the lower range of the circulating TF level [24, 25]. FVIIa can initiate coagulation not only in a TF-dependent way but also by binding directly to PL surfaces, e.g. to platelets [6]. Because the PL concentration we used was also low, we presumed that the assay conditions were not optimal for an FVIIa-induced bypassing of the FVIII inhibitor. Therefore, we investigated the effect of various TF levels on TG in the presence of therapeutic doses equivalent to a concentration of FEIBA $(0.8 \mathrm{U} / \mathrm{ml})$ and $\mathrm{rFVIIa}(1 \mu \mathrm{g} / \mathrm{ml})$. We found that low concentrations of TF increased the thrombin-generating capacity of FVIIa, without substantially influencing the effect of FEIBA (fig. 5). The addition of higher TF concentrations dose-dependently increased the peak thrombin resulting from both preparations. Recent data show that under specific conditions, which are not yet known, the TF available in the circulation in the form of microvesicles [26] and the TF released from the platelets upon their activation [27] might be sufficient to substantially contribute to the procoagulant effect of FVIIa in vivo.

When thrombin generation was measured at different times in haemophilia patients with inhibitor after treatment with single doses of FEIBA, an increased thrombin generation was observed within 15-30 min after injection, which gradually returned to baseline values $8-12 \mathrm{~h}$ after treatment [17]. Therefore, this TG assay enables the monitoring of the in vivo thrombin-generating capacity of FVIII-bypassing agents and thus might help to optimize the treatment.

\section{Acknowledgements}

We are grateful to Elise Langdon-Neuner for editorial assistance and Sylvia C. Maurer for graphical assistance. 


\section{References}

1 Lusher JM: Use of prothrombin complex concentrates in management of bleeding in hemophiliacs with inhibitors: Benefits and limitations. Semin Hematol 1994;31(suppl 4):49_ 52.

2 Roberts HR: The use of agents that by-pass factor VIII inhibitors in patients with haemophilia. Vox Sang 1999;77(suppl 1):38-41.

3 Sultan Y, Kazatchkine MD, Algiman M, Dietrich $G$, Nydegger $U$ : The use of intravenous immunoglobulins in the treatment of factor VIII inhibitors. Semin Hematol 1994;31:6566.

4 Knöbl P, Derfler K, Korninger L, Kapiotis S, Jäger U, Maier-Dobersberger T, Hörl W, Lechner K, Pabinger I: Elimination of acquired factor VIII antibodies by extracorporal antibody-based immunoadsorption (Ig-Therasorb). Thromb Haemost 1995; 74:1035-1038.

5 Hay CRM, Bolton-Maggs P: Porcine factor VIII:C in the management of patients with factor VIII inhibitors. Transfus Med Rev 1991;5: 145-151.

6 Hoffman M, Monroe DM, Roberts HR: Human monocytes support factor $\mathrm{X}$ activation by factor VIIa, independent of tissue factor: Implications for the therapeutic mechanism of high dose factor VIIa in hemophilia. Blood 1994;83. 38-41.

7 Turecek PL, Varadi K, Gritsch H, Auer W, Pichler L, Eder G, Schwarz HP: Factor Xa and prothrombin: Mechanism of action of FEIBA. Vox Sang 1999;77(suppl 1):72-79.

8 Gallistl S, Cvirn G, Leschnik B, Muntean W: Respective roles of factors II, VII, IX, and X in the procoagulant activity of FEIBA. Blood Coagul Fibrinolysis 2002;13:653-655.

9 Ingerslev J, Christiansen K, Calatzis A, Holm M, Ebbesen LS: Management and monitoring of recombinant activated factor VIII. Blood Coagul Fibrinolysis 2000;11(suppl 1):25-29.

10 Yoshioka A, Nishio K, Shima M: Thrombelastgram as a hemostatic monitor during recombinant factor VIIa treatment in hemophilia A patients with inhibitor to factor VIII. Haemostasis 1996;26(suppl 1):139-142.
11 Hemker HC, Willems GM, Béguin S: A computer assisted method to obtain the prothrombin activation velocity in whole plasma independent of thrombin decay processes. Thromb Haemost 1986;56:9-17.

12 Schwarz HP, Rengs H, Elsinger F: An assay for the bioavailability of FEIBA (abstract). Kyoto Satellite Symposia of the 12th ISTH Congress, Kyoto, 1989.

13 Gill C, Schwarz HP, Wentz MA, Montgomery RR: Platelet prothrombinase activity may predict successful activated prothrombin complex concentrate (FEIBA) treatment. Blood 1990; 76(suppl 1):399a.

14 Sultan Y, Loyer F: In vitro evaluation of factor VIII-bypassing activity of activated prothrombin complex concentrate, prothrombin complex concentrate, and factor VIIa in the plasma of patients with factor VIII inhibitors: Thrombin generation test in the presence of collagenactivated platelets. J Lab Clin Med 1993;121: 444-452.

15 Hemker HC, Wielders S, Kessels H, Béguin S: Continuous registration of thrombin generation in plasma, its use for the determination of the thrombin potential. Thromb Haemost 1993; 70:617-624.

16 Madlener K, Gissel B, Brackmann H, Pötzsch $\mathrm{B}$ : The endogenous thrombin generation potential (ETB) is an accurate and rapid monitoring method for recombinant factor VIIa. Ann Hematol 2000;79(suppl I):A46.

17 Váradi K, Negrier C, Berntorp E, Astermark J, Bordet JC, Morfini M, Linari S, Schwarz HP, Turecek PL: Monitoring the bioavailability of FEIBA with a thrombin generation assay. $\mathrm{J}$ Thromb Haemost 2003, in press.

18 Váradi K, Siekmann J, Turecek PL, Schwarz HP, Marder VJ: Phospholipid-bound tissue factor modulates both thrombin generation and APC-mediated factor Va inactivation. Thromb Haemost 1999;82:1673-1679.
19 Hemker HC, Giesen PLA, Ramjee M, Wagenvoord R, Béguin S: The thrombogram: Monitoring thrombin generation in platelet rich plasma. Thromb Haemost 2000;83:589-591.

20 Kristensen AT, Madsen MT, Nielsen GN, Ezban M: Recombinant human FVIIa dose dependently shortens the bleeding time in a rabbit model of antibody induced hemophilia A. Thromb Haemost 1999(suppl):328.

21 Chuansumrit A, Sri-Udomporn N, Srimuninnimit V, Juntarukha R: A single high dose of recombinant factor VIIa combining adjuvant therapy for controlling bleeding episodes in haemophiliacs with inhibitors. Haemophilia 2001;7:532-534.

22 Cooper HA, Jones CP, Campion E, Roberts HR, Hedner U: Rationale for the use of high dose rFVIIa in a high-titre inhibitor patient with haemophilia B during major orthopaedic procedures. Haemophilia 2001;7:517-522.

23 Kenet G, Lubetsky A, Gitel S, Luboshitz J, Varon D, Martinowitz U: Treatment of bleeding episodes in patients with hemophilia and an inhibitor: Comparison of two treatment protocols with recombinant activated factor VII. Blood Coagul Fibrinolysis 2000;11(suppl 1): 35-38.

24 Fareed J, Callas DD, Hoppensteadt D, Bermes EW Jr: Tissue factor antigen levels in various biological fluids. Blood Coagul Fibrinolysis 1995;6(suppl 1):32-36.

25 Koyama T, Nishida K, Ohdama S, Sawada M, Murakami N, Hirosawa S, Kuriyama R, Matsuzawa K, Hasegawa R, Aoki N: Determination of plasma tissue factor antigen and its clinical significance. Br J Haematol 1994;87:343347.

26 Scholz T, Temmler U, Krause S, Heptinstall S, Lösche W: Transfer of tissue factor from platelets to monocytes: Role of platelet-derived microvesicles and CD62P. Thromb Haemost 2002;88:1033-1038.

27 Siddiqui FA, Desai H, Amirkhosravi A, Amaya M, Francis JL: The presence and release of tissue factor from human platelets. Platelets 2002;13:247-253. 